\title{
Heart rate variability: Highlights from hidden signals
}

\author{
Mücahid Yilmaz ${ }^{1 *}$, Hidayet Kayançiçek ${ }^{2}$ and Yusuf Çekici $^{3}$ \\ ${ }^{1}$ Elazı̆̆ Education and Research Hospital, Department of Cardiology, Turkey \\ ${ }^{2}$ Elazığ Medical Park Hospital, Affiliated to Istinye University, Department of Cardiology, Department of Cardiology, Turkey \\ ${ }^{3}$ Dr. Ersin Arslan Education and Research Hospital, Department of Cardiology, Turkey
}

\begin{abstract}
The heart rate variability (HRV), which can provide information about the balance between the sympathetic and the parasympathetic system, is accepted as an indicator of autonomic tone, which is effective on the heart. Neural remodeling developing in hearts that are affected by various diseases leads to imbalance in the autonomic activity. These changes that may occur in the autonomic nervous system may lead to ventricular arrhythmia and sudden cardiac death through negatively affecting the cardiac rhythm. HRV has been evaluated in many cardiac, neurological and rheumatological diseases in recent years and has come into the foreground as an important marker of mortality. In this review, we aimed to introduce the parameters used in HRV measurements and analyze the conditions that could influence these measurements (maneuver, diseases or drugs, etc).
\end{abstract}

\section{Introduction}

It is known that an imbalanced autonomic nervous system in the form of increased sympathetic activity affects cardiac electrophysiology and leads to ventricular arrhythmias and sudden cardiac death. Neural remodeling in hearts affected by various diseases causes these imbalances in autonomic activity. Heart rate variability (HRV), an indirect indicator of tonic autonomic interactions at the sinus node level, is used as an indicator for neural control of the heart [1]. It is mainly an efferent system that transmits impulses from the central nervous system to the peripheral organs [2]. Thus, it controls heart rate, contraction strength of the heart, contraction and dilation of vessels, contraction and loosening of smooth muscles in various organs and secretion from endocrine and exocrine glands [2]. The autonomic nervous system (ANS) is anatomically and functionally divided into two subsystems: the sympathetic nervous system (SNS) and parasympathetic nervous system (PSNS). The preganglionic fibers of PSNS originate from the brain stem and are known as craniosacral fibers [2]. Vagus or 10th cranial nerve conveys fibers to the heart, lungs and other organs, and generates the major parasympathetic innervation of these organs. PSNS causes a decrease in heart rate and blood pressure [2]. The nuclei of sympathetic preganglionic nerve fibers are found in the sympathetic ganglion chain situated in the lateral horns between T1 and L2 of the spinal cord. Unlike PSNS, the SNS allows the body to give necessary reactions in case respiratory insufficiency or hemodynamic impairment develops or briefly to survive. In such cases, the SNS elevates heart rate, blood pressure and cardiac output; causes a shift of blood from the skin and splanchnic bed to the striated muscles, expansion in the bronchi and reduction in metabolic activity [2].

Other terms have been used in the literature to describe oscillations in successive phases of cardiac cycles, such as heart period variability, RR interval variability, RR interval tachogram. These more appropriately emphasize the fact that the analysed factor is not the heart rate itself but the interval between successive beats. However, "Heart rate variability" has become the conventionally accepted term to describe variations of both instantaneous heart rate and RR intervals [3]. Heart rate variability was first described in 1847 as an increase in heart rate with inspiration and a decrease in heart rate with expiration. The clinical significance of HRV was noticed in 1963 by showing that the alterations in interbeat intervals just before fetal death could be observed immediately before the alterations in heart rate itself [1]. In 1965, it was introduced by Hon and Lee into clinical practice to assess the fetal distress by monitoring the alterations in intervals between the beats without changing the heart rate [4]. In the 1970s, Ewing et al. used heart rate variability to identify autonomic neuropathy in diabetic patients [5]. Heart rate variability (HRV), which we can describe as cyclic alterations in the rate of sinus rhythm, is considered as a measure of cardiac autonomic tone and as a non-invasive indicator of the cardiorespiratory system, since it provides information about sympathetic-parasympathetic balance [6]. Physiological increase in the variability between heartbeats is a desirable condition, and concordantly decrease in HRV is associated with worse cardiovascular prognosis [7].

\section{Measurement of heart rate variability}

The variations in heart rate can be calculated by a number of methods. To classify these, we can collect them under two main topics as linear and non-linear methods. Linear methods contain time-based and frequency-based methods [8].

\section{A. Linear methods}

1. Time-domain methods

a. Statistical

b. Geometric

${ }^{\star}$ Correspondence to: Mücahid Yılmaz, Elazı̆̆ Education and Research Hospital, Department of Cardiology, Turkey, E-mail: mucahid.yilmaz@mynet.com

Key words: Heart rate variability, mortality, autonomic nervous system

Received: October 08, 2018; Accepted: October 18, 2018; Published: October 22, 2018 
2. Frequency domain methods
a. Short-term recordings
b. Long-term recordings

\section{Time-domain}

In this method, the heart rate taken at any time or the interval between successive normal complexes is determined. In a continuous ECG record, each QRS complex is detected, and the normal-tonormal $(\mathrm{NN})$ intervals or the instantaneous heart rate is determined. In general, time domain methods are ideal for the analysis of shortterm recordings. These values may be expressed in original units or as the natural logarithm ( $\mathrm{Ln})$ of original units to achieve a more normal distribution [9]. Time-based methods can be statistical or geometric $[3,10]$.

a. Statistical Methods: From a series of instantaneous heart rates or cycle intervals, particularly those recorded over longer periods (traditionally 24 hours), more complex statistical time domain measures can be calculated. These may be divided into two classes: 1) those derived from direct measurements of the $\mathrm{NN}$ intervals or instantaneous heart rate, 2) those derived from the differences between $\mathrm{NN}$ intervals. The simplest variable calculated is the standard deviation of the NN intervals (SDNN), that is, the square root of variance. Since variance is mathematically equal to total power of spectral analysis, SDNN reflects all the cyclic components responsible for variability in the period of recording. However, the duration of recordings used to determine the SDNN values (and similarly other measurements of HRV) should be standardized [8].

b. Geometric Methods: The sequence of NN intervals can be expressed by a geometric pattern. There are two general approaches [8].

1) Basic measurement of the geometric pattern. Example: The width of the distribution histogram at the specified level is converted into the measure of HRV. Based on a histogram of RR intervals with bin size $1 / 128 \mathrm{sec}$, the HRV triangular index (HRVI) is given by the most frequent value $\mathrm{X}$ (mode) with its absolute frequency Y: HRV triangular index: $=\mathrm{D} / \mathrm{Y}[11]$ (Figure 1).

2) The geometric pattern is interpolated by a mathematically defined shape. Example: Approximation of the distribution histogram by a triangle: A triangular interpolation of the discrete distribution of RR intervals (histogram counts) is used for the TINN [Triangular interpolation of RR (or NN interval) histogram] measure: TINN = BA [12] (Figure 1).

Statistical and geometric time domain methods and its explanations is showed in Table $1[6,11,12]$.

\section{Frequency Domain}

This method distinguishes the heart rate signals according to their frequency and intensity. It provides information on the amount of all changes in the heart rate by taking advantage of periodic heart rate oscillations at various frequencies. Various spectral methods have been applied since 1960s [13]. Power spectral density (PSD) analysis provides the basic information of how power (variance) distributes as a function of frequency. Basically, the records are approached with short term periods ranging from 2 to 5 minutes or 24-hour long term periods, then 4 main spectral components are calculated $[12,14,15]$. These components are described as ultra-low frequency (ULF), very low frequency (VLF), low frequency (LF) and high frequency (HF) (Figure 2). However, ULF is not included in the standard Holter programs. The spectral analyzes of HRV signals are considered as an uninterrupted indicator of sympathetic and parasympathetic activities of ANS $[6,16]$.

As can be seen in, four basic spectral components can be distinguished in the spectrum of HRV recordings. ULF, VLF, LF, HF (Figure 2).

1. Ultra Low Frequency (ULF): includes the frequency components below $0.0033 \mathrm{~Hz}$. Its characteristics are not fully understood. It is scarcely used in clinical practice. The recording time is long-term (entire 24 hours) [17].

2. Very Low Frequency (VLF): It includes the frequency components in the range of $0.0033-0.04 \mathrm{~Hz}$. Although it is not exactly known how this component has occurred, it is considered to be originated from thermal and hormonal control along with vasomotor activity, and not associated with ANS. The recording time is short-term (1-5 $\mathrm{min}$ ) and long-term (entire 24 hours) $[3,17,18]$.

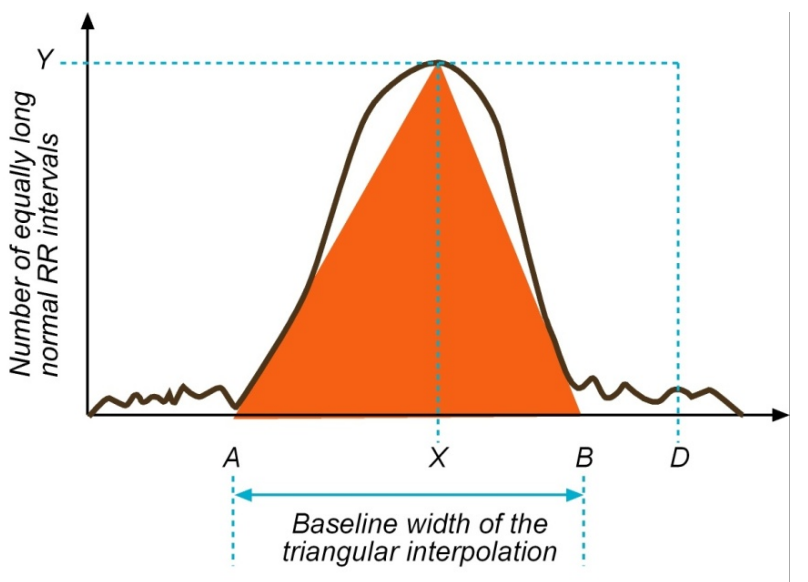

Duration of normal RR intervals

Figure 1. HRV triangular index (HRVI) measurement

HRVI: D/Y (Total number of all NN intervals/ Y). For measurement a discrete scale is constructed on the horizontal axis and named the sample density distribution (D) which assigns the number of equally long normal RR intervals to each value of their lengths. Y is the maximum sample density distrubition (D). The formula obtained from division of the integral of the density distribution (the number of total NN intervals) to the maximum of the density distribution (Y). For the computation of the TINN measure, the values A and B are established on the time axis and a multilinear function $\mathrm{q}$ constructed such that $\mathrm{q}(\mathrm{t})=0$ for $\mathrm{t} \leq \mathrm{A}$ and $\mathrm{t} \geq \mathrm{B}$ and $\mathrm{q}(\mathrm{X})=\mathrm{Y}$, and such that the integral $\int 0+\infty=(\mathrm{D}(\mathrm{t})-\mathrm{q}(\mathrm{t})) 2 \mathrm{dt}$ is the minimum among all selections of all values $\mathrm{A}$ and $\mathrm{B}$. The TINN measure is obtained by the formula $\mathrm{TINN}=\mathrm{B}-\mathrm{A}[6]$.

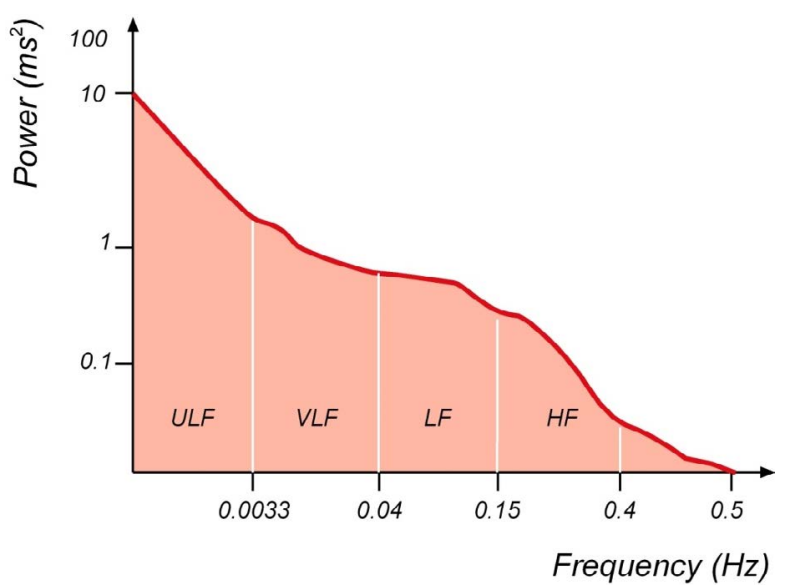

Figure 2. A power spectral density estimation example obtained from the entire 24-h interval of a longterm holter recording 
Table 1. Time domain measurement definitions of heart rate variability

\begin{tabular}{|l|l|}
\hline VARIABLE (Unit) & Explanation \\
\hline NN (ms) & The cycle length between two beats \\
\hline Day/night difference (msec) & The day-night difference of average NN intervals \\
\hline SDNN (ms) & $\begin{array}{l}\text { It is the standard deviation of all normal RR intervals in the entire 24-hour ECG record. The standard deviation of NN (SDNN) reflects } \\
\text { the parasympathetic component of the autonomic function. It reflects the decrease in SDNN, decreased vagal activity and increased } \\
\text { sympathetic activity of the sinus node. }\end{array}$ \\
\hline SDNN Index (ms) & It is the average of the standard deviations of all normal RR intervals for all 5-minute segments in a 24-hour ECG record. \\
\hline SDANN (ms) & $\begin{array}{l}\text { It is the standard deviation of the average NN intervals calculated over short periods, usually } 5 \text { minutes, which is an estimate of the } \\
\text { alterations in heart rate due to cycles longer than 5 minutes. }\end{array}$ \\
\hline $\begin{array}{l}\text { RMSSD(root mean square of successive } \\
\text { differences)(ms) }\end{array}$ & $\begin{array}{l}\text { It is the square root value of the total squared differences of successive NN intervals with sinus conduction. It is considered as an } \\
\text { important indicator of parasympathetic activity. }\end{array}$ \\
\hline SDSD (ms) & It is the standard deviation of differences between successive normal cycles. \\
\hline NN50 Number & It is the number of NN intervals between which the difference occurs greater than 50 msec throughout the entire record \\
\hline PNN50 $(\%)$ & $\begin{array}{l}\text { It is obtained by dividing NN50 number into the total number of NN.It shows the percentage of differences greater than 50 msec between } \\
\text { successive normal RR intervals in a 24-hour ECG record. It predominantly reflects the parasympathetic activity. }\end{array}$ \\
\hline Triangular Index(HRVI) & Number of total NN intervals/ number of NN intervals in the modal bin \\
\hline TINN(ms) & Baseline width of the RR interval histogram \\
\hline HR Max - HR Min(bpm) & Average difference between the highest and lowest heart rates during each respiratory cycle \\
\hline
\end{tabular}

3. Low Frequency (LF): It includes the frequency range between $0.04 \mathrm{~Hz}$ and $0.15 \mathrm{~Hz}$ and is consisting of a combination of sympathetic and parasympathetic effects $[3,19]$. It is associated with thermoregulation and peripheral vasomotor activity. The recording time is short-term (1-5 min) and long-term (entire 24 hours) [17].

4. High Frequency (HF): It includes the frequency range between $0.16 \mathrm{~Hz}$ and $0.4 \mathrm{~Hz}$. It is considered that it is modulated by the parasympathetic activity of ANS and that is the major determinant of respiratory sinus arrhythmia. The recording time is short-term (1-5 $\mathrm{min}$ ) and long-term (entire 24 hours) $[6,3,16,19]$.

There are publications reporting the existence of the MF (Middle Frequency) band other than these bands. It is known that it provides information about sympathetic and parasympathetic tonus and that the recording time is short-term (1-5 $\mathrm{min}$ ) and long-term (entire 24 hours) [17]. However, it could not gain a place in routine use.

Some researchers use normalized unit (nu) values as a base for $\mathrm{LF}$ and HF values while conducting their studies. It is in the form of LF/ (Total Power-VLF) x100 for formula LF, and HF/ (Total PowerVLF) $\mathrm{x} 100$ for HF [3]. Total power is the sum of the powers of the five frequencies mentioned above. From these frequency bands, HF, MF and LF bands account for $5 \%$ of total power [12]. Although ULF and VLF form the remainder of total power, their clinical use is limited since their physiological characteristics are not well known. Researchers generally use the LF/HF ratio $[12,17]$.

LF/HF ratio: It is another parameter that needs to be considered other than the four basic parameters mentioned above. There is a correlation between LF and HF. The ratio of LF to HF reflects the sympathovagal balance. An increased LF/HF ratio indicates low vagal activation [3]. In healthy subjects, $L F$ and HF have a circadian pattern with reciprocal fluctuations. In the daytime LF increases, in the nighttime HF increases. LF increases during 90-degree tilt, mental stress, standing, occlusion of coronary arteries, moderate exercise, and occlusion of carotid arteries. HF increases in cases of respiration, cold application on the face and rotational stimulation [12].

Since the measurements of heart rate variability are assessed by various investigators by various measurements, interpretation of the obtained data may be different or incorrect. In order to eliminate this complexity, the ESC (European Society of Cardiology) has published a guideline for HRV [6]. According to that:
- Under stable conditions, time measurements should be made in 24hour long-term recordings and frequency measurements should be made in 5-min recordings.

- The use of four of the time measurements is always required. These include SDNN and the triangular index reflecting overall HRV; SDANN showing long-term components and RMSSD showing short-term components.

- The measurement period should be at least ten times more than the LF band wavelength. In order to standardize this, at least $5 \mathrm{~min}$ rule has been established.

The normal ranges of some of used time domain and frequency domain measurements are shown in Table 2 [6].

\section{B) Non-Linear methods}

These measurements allow us to quantify the unpredictability of a time series and act different compared to linear systems [8]. They are determined by complex interactions of hemodynamic, electrophysiological and humoral variables, as well as by autonomic and central nervous regulations [3]. The study of HRV has been influenced by dynamical systems theory, the study of fractal systems and chaos theory. Main points in these systems are fragility and robustness. System robustness is often defined as the quality of a biological system to maintain its components, structure, and function despite both external changes and endogenous fluctuations [20]. Fragility is connected to robustness. A property of complex systems is a conservation of sensitivity. When robustness is improved in one area, it leads to increased fragility in another [21]. This structure causes to cascading failures initiated by tiny perturbations which may lead to a complete breakdown, or to a fundamental system change. Key elements to study complexity are mathematical models and time-series analysis. Time-series tools is the most used arguements for HRV analysis in clinical practice [20]. For data representation, Lorenz plots (or Poincaré plots), low-dimension attractor plots, singular value decomposition, and attractor trajectories have been used. For other quantitative descriptions, the D2 correlation dimension, Lyapunov exponents, and Kolmogorov entropy have been employed [3].

Lorenz plot (or Poincaré plot) is the most used method among the non-linear methods. This method is a geometrical representation of a time series into a cartesian plane, where the values of each pair of successive elements of the time series define a point in the plot 
Table 2. Normal values of frequently used indexes in heart rate variables

\begin{tabular}{|l|c|}
\hline INDEX (Unit) & NORMAL RANGE \\
\hline Time measurements in 24-hour recordings & \\
\hline SDNN $\left(\mathrm{ms}^{2}\right)$ & $141 \pm 39$ \\
\hline SDANN $\left(\mathrm{ms}^{2}\right)$ & $127 \pm 35$ \\
\hline RMSSD $\left(\mathrm{ms}^{2}\right)$ & $27 \pm 12$ \\
\hline HRV Triangular Index & $37 \pm 15$ \\
\hline SDSD $\left(\mathrm{ms}^{2}\right)$ & $141 \pm 39$ \\
\hline pNN50 $(\%)$ & $20 \pm 16$ \\
\hline Spectral measurements in 5-min recordings & \\
\hline Total Power $\left(\mathrm{ms}^{2}\right)$ & $3466 \pm 1018$ \\
\hline VLF $\left(\mathrm{ms}^{2}\right)$ & $627 \pm 215$ \\
\hline LF $\left(\mathrm{ms}^{2}\right)$ & $1170 \pm 416$ \\
\hline HF $\left(\mathrm{ms}^{2}\right)$ & $975 \pm 203$ \\
\hline LF/HF ratio $\left(\mathrm{ms}^{2}\right)$ & $1.5-2.0$ \\
\hline
\end{tabular}

[22] (Figure 3). The Poincaré plot is used to quantify recurrence, selfsimilarity, or periodicity in a time series. It is based on the concept of a return map, and in its simplest form provides a means for displaying sequential pairs of points [23-26].

Some most used non-linear methods detailed in Table 3 [8].

\section{Some conditions that cause heart rate variability to change}

With HRV method, efferent cardiac sympathetic - parasympathetic modulation can be measured at the sinus node level. It has been shown in experimental studies that myocardial level effects of efferent neural stimulation could be measured with changes in effective refractory period [27]. HRV analyzes provide a well-defined and non-invasive good option for the examination of autonomic nervous system modulation [6]. The modulation of heart rate is under the control of complex regulatory mechanisms including the nervous system, the endocrine system and the cardiovascular system [6]. The alterations in autonomic balance may be associated with the onset of the disease and the alterations observed during cardiac autonomic control, which are measured by heart rate variability. HRV helps to define the subgroups (atherosclerosis, hypertension, diabetes mellitus) that have higher risk for cardiovascular morbidity and mortality [28]. This condition has been proved in patients with hypertension, diabetes, coronary artery disease, chronic heart failure, and previous myocardial infarction [2934]. Although its mechanism has still not been fully clarified, it is linked to advanced age and decrease in HRV values. In addition, HRV values measured in male gender were reported to be higher than in women [28].

\section{Myocardial infarction}

Decrease in HRV identified after acute myocardial infarction has been reported to be a powerful indicator in terms of mortality and arrhythmic complications in these cases $[3,31]$. This predictive value of HRV has been found to be independent of other post-infarction risk factors. This characteristic of HRV cannot simply be attributed to only hyperfunction of the sympathetic system and/or vagal withdrawal due to poor ventricular performance. Decrease in HRV is indicative of suppressed vagal activity, which is closely associated with the pathogenesis of ventricular arrhythmias and sudden cardiac deaths [32]. It was first reported by Kleiger et al, that decrease in the SDNN value observed in post-myocardial infarction period was associated with clinical and demographic characteristics, increased mortality rate independent of ventricular ectopic activity and left ventricular ejection fraction [33]. Similar results were also observed in the study of ATRAMI (Autonomic Tone and Reflexes After Myocardial Infarction).
This study conducted with 1300 cases showed that decreased HRV $(\mathrm{SDNN}<70 \mathrm{msec})$ levels are a very important and independent predictor of total cardiac mortality [6]. The combination of decreased left ventricular ejection fraction with decreased SDNN significantly increases the predictive value [6].

\section{Systolic dysfunction}

It may also be benefited from spectral parameters of HRV. In a study of patients with low ejection fraction (mean EF: $24 \pm 7 \%$ ), decrease in LF component has been determined as an independent predictor of sudden death independently from variables including clinical evaluation, right heart catheterization, exercise and blood tests [34]. When the combination of frequent premature ventricular contractions and low LF detected by Holter records is made, it was observed that the sudden death percentage in a three-year period was observed to be very high compared to the group in which no combination was made $(23 \%$ $3 \%$, respectively, $\mathrm{p}=0.001$ ) [34].

\section{Diabetes mellitus}

In diabetic neuropathy that can be observed in diabetes mellitus, a decrease is observed in HRV parameters [35]. It has been reported that a decrease in LF and HF values was detected before autonomic neuropathy signs have been observed in diabetic patients [6]. In autonomic neuropathy, one of the early complications of diabetes mellitus, neuronal degeneration is observed both in sympathetic and small parasympathetic nerve fibers. The expected 5-year mortality rate after clinical neuropathy arises is about $50 \%$. Therefore, early detection of subclinical autonomic dysfunction by HRV analysis is important in terms of risk analysis and treatment plan [36].

\section{Mitral Valve Prolapse (MVP)}

The association between the prolapse severity and HRV parameters were investigated by Karakaya I, et al. by measuring the low frequency (LF) reflecting sympathovagal activity, high frequency (HF) reflecting parasympathetic activity, and LF/HF ratio reflecting the sympathovagal

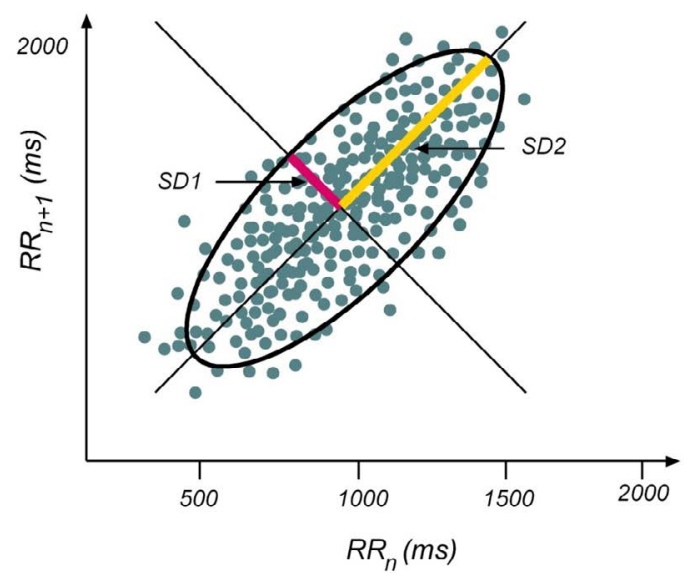

Figure 3. Illustrative example of a Poincaré plot

The Poincare plot is a map of points in Cartesian coordinates that is constructed from the values of the RR intervals. Each point is represented on the $\mathrm{x}$-axis by the previous normal $R R$ interval and on the $y$-axis by the following RR interval [24]. An ellipse fits along the line of identity (dotted line) [23]. SD1 is the short-term variability and SD2 is the long-term variability. The transverse axis (SD1) reflects beat-to-beat variation, while the longitudinal axis (SD2) reflects the overall fluctuation. The SD1/SD2 shows the ratio between the shortand long-term variability among the RR intervals and named Cardiac Sympathetic Index $[25,26]$. 
Table 3. Non- linear methods and descriptions

\begin{tabular}{|c|c|l|}
\hline Parameter & Unit & Description \\
\hline $\mathrm{S}$ & $\mathrm{ms}$ & Area of the ellipse which represents total HRV \\
\hline $\mathrm{SD} 1$ & $\mathrm{~ms}$ & $\begin{array}{l}\text { Poincaré plot standard deviation perpendicular the line of identity: An index of the instantaneous recording of the variability of beat-to-beat and } \\
\text { represents the parasympathetic activity }\end{array}$ \\
\hline $\mathrm{SD} 2$ & $\mathrm{~ms}$ & Poincaré plot standard deviation along the line of identity: the SD2 index represents the long-term HRV and reflects the overall variability \\
\hline $\mathrm{SD} 1 / \mathrm{SD} 2$ & $\%$ & $\begin{array}{l}\text { Ratio of SD1-to-SD2: The SD1/SD2 shows the ratio between the short- and long-term variation among the RR intervals and named Cardiac } \\
\text { Sympathetic Index }\end{array}$ \\
\hline ApEn & & Approximate entropy, which measures the regularity and complexity of a time series \\
\hline SampEn & & Sample entropy, which measures the regularity and complexity of a time series \\
\hline DFA $\alpha 1$ & & Detrended fluctuation analysis, which describes short-term fluctuations \\
\hline DFA $\alpha 2$ & & Detrended fluctuation analysis, which describes long-term fluctuations \\
\hline $\mathrm{D}_{2}$ & & Correlation dimension, which estimates the minimum number of variables required to construct a model of system dynamics \\
\hline
\end{tabular}

balance, and the MVP group was divided into three subgroups: mild, moderate and severe prolapse, and compared to the population with normal mitral valve morphology, LF values were found to be lower in the moderate and severe MVP groups than in the control group ( $\mathrm{p}<0.05, \mathrm{p}<0.001$, respectively) [37]. Moreover, when the MVP groups were assessed among themselves it was found that severe MVP group had lower LF level than the mild MVP group $(\mathrm{p}<0.01)$ and HF values were lower in severe MVP group than in control group ( $p<0.01)$, and no significant difference was detected among patient groups $(\mathrm{p}>0.05)$. The $\mathrm{LF} / \mathrm{HF}$ value of the severe MVP group was found to be lower compared to the control group $(\mathrm{p}<0.05)$ [37]

\section{Heart transplantation}

Although no significant spectral components were not reported in cases of new heart transplants, HRV values have been reported to be significantly decreased [38]. Observation of different spectral components in transplant patients may be the indicator of cardiac reinnervation [39]. Reinnervation can be observed up to 2 years after the transplant and is originated from the sympathetic nervous system [6]. Halpert I et al. reported that patients, who had transplantation earlier than 36 months, had a lower mean heart rate and an increased SDNN index and higher LF and HF values compared to early posttransplant patients [40].

\section{Smoking}

Alyan Ö, et al. investigated the association between smoking and autonomic activity and reported that the LF and LF/HF ratio was significantly higher in smokers; and that they found significantly lower SDNN, SDANN, RMSSD and HF values, and that smoking disrupts sympathovagal balance in healthy subjects [41].

\section{Hypertension}

Thayer JF, et al. reported that modifiable (such as work stress) and unmodifiable (such as hypertension, obesity, family history) risk factors for cardiovascular disease were linked to decreased heart rate variability parameters [42]. Similar findings were expressed by Şahiner, et al. and it was found that SDNN and PNN50 were significantly lower in hypertensive patients, on the other hand, the LF and LF/HF ratios were higher in hypertensive subjects [43].

\section{Obstructive sleep apnea}

Sarıkaya S, et al. reported that they found lower SDNN values in the sleep apnea syndrome group compared to the healthy group, and higher LF and LF/HF values of frequency-based values in patients with sleep apnea syndrome compared to the control group, and lower HF values in sleep apnea syndrome patients compared to the control group, and that patients should be assessed carefully in terms of cardiac arrhythmias [44].

\section{Parkinson's disease:}

Devos D, et al. divided 30 Parkinson's patients into three groups: mild (with mildly impaired L-Dopa activity; the group that have got the disease earlier than 2 years), moderate (the group with moderately impaired L-Dopa activity) and severe (the group with concomitant motor complications), and found that there was no difference between the mild Parkinson's disease (PD) group and the control group in terms of HRV values, and that there was a decrease in diurnal LF and LF/ HF power values of the moderate and severe (PD) groups, and that there was a decrease in HF and pNN50 power (the nocturnal vagal indicators) of the severe group, and stated that these findings could indicate cardiovascular dysautonomia in Parkinson's disease [45].

\section{Exercise}

It has been reported that SDNN values, RMSSD values and triangular index values from time-domain parameters respectively increased with exercise [46].

\section{Beta blockers}

Beta blockers increase the heart rate. However, there is no sufficient data related to its the effects on HRV in the post-myocardial period. It has been reported that LF increase observed in the morning is prevented by beta blockade [12].

\section{Antiarrhythmics}

Decrease in HRV increases the mortality rate independently of previous myocardial infarction (by increasing the risk for arrhythmia) [47]. Drugs used for anti-arrhythmic purposes affect HRV. The use of propafenone and flecainide in patients with chronic ventricular arrhythmia results in a decrease in the time-domain parameters of HRV [48]. It was reported by another study that propafenone decreased HRV. There was a decrease in LF more than HF and accordingly significantly decreased LF/HF ratio observed in this study [49]. Bigger JT, et al. reported that flecainide, encainide and moricizine decreased HRV in patients who had myocardial infarction, however there was no link between the mortality and the decrease in HRV [50].

\section{Scopolamine and Atropine}

Low-dose muscarinic receptor blockade with agents such as scopolamine and atropine lead to an increase in vagal efferent activity. Scopolamine causes pharmacological modulation of neural activity by increasing the vagal activity, and leads to a significant increase in HRV, however the results of long-term treatment with scopolamine are unknown [6]. 


\section{ACE inhibitors}

Parasympathetic activity is increased by their use in heart failure. ACE inhibitors prevent the inhibition of central vagal output that is caused by AT-II and increase the baroreceptor sensitivity. As a result of these, HRV is positively affected. ACE inhibitors do not affect HRV in healthy individuals [12].

\section{Calcium channel antagonists}

Diltiazem decreases the sympathetic activity, however, unlike betablockers, it does not increase the parasympathetic activity. The LF/HF ratio is reduced [51].

\section{Digoxin:}

Digoxin mainly decreases LF. The LF/HF ratio is reduced. No change occurs in the HF band. These changes are not observed in healthy individuals [6].

\section{Provocative maneuvers}

Selective changes are observed in HRV components in autonomically provocative maneuvers such as dobutamine stress test, hand-grip, tilt table test. There are authors who linked syncope to a significant LF increase developed during the tilt table test $[12,52]$.

\section{Mobile phone}

Tamer A et al, investigated the effects of mobile phone on HRV in the closest position and investigated the HRV parameters with a 30 min of exposure (SNN50total, SDNN, SDNNI, SDANN, RMSDD, and triangular index from time-domain parameters were used) in healthy adult subjects while the mobile phone was in different modes (mobile phone on, off and search active) and in the closest position to the heart, that is, in precordial area and reported that mobile phone signals did not affect the heart rate, blood pressure, and did not cause cardiac autonomic dysfunction [53]. However, Yıldız M, et al. investigated the effects of mobile phones on Power Spectral Density (PSD) of HRV and detected an increase in HF area power $(\mathrm{p}<0.01)$, which is known to arise as a result of parasympathetic activity of the autonomic nervous system, and detected an increase in the central frequency of the LF region $(\mathrm{p}<0.05)$, which is known to arise as a result of the combination of sympathetic and parasympathetic (vagal) activity [54]. Wile, et al. reported a significant difference in $\mathrm{LF} / \mathrm{HF}$ ratio during heart rate change frequency-plane analyzes of subjects who were exposed to $1 \mathrm{~W} / \mathrm{kg}$ of electromagnetic energy for 10 minutes [55]. Although no significant difference in LF/HF ratio was observed in the study of Yildız, et al. it supports the study of Wile et al, in terms of indicating that changes may occur in the regulation mechanisms of heart rate [54].

While the output power for mobile phones is around $250 \mathrm{~mW}$ during talking, mobile phone tries to reach the base station with the highest output power ( $<2 \mathrm{~W}$ for $900 \mathrm{MHz},<1 \mathrm{~W}$ for $1800 \mathrm{MHz}$ ) during the call [56]. The limit values for uncontrolled exposure in terms of electrical field were determined to be $42 \mathrm{~V} / \mathrm{m}$ for $900 \mathrm{MHz}$ and 57 $\mathrm{V} / \mathrm{m}$ for $1800 \mathrm{MHz}$ by the International Commission on Non-Ionizing Radiation Protection (ICNIRP). Electric field intensity of a mobile phone with $2 \mathrm{~W}$ output power that functioning at $1800 \mathrm{MHz}$, was measured to be $400 \mathrm{~V} / \mathrm{m}$ at $2.2 \mathrm{~cm}$ distance [56]. Considering that many mobile phones used in daily life have a power output of $2 \mathrm{~W}$ or more, it is obvious that the issue of whether mobile phones have a direct effect on the parameters of HRV or not deserves further researches. Within this context, longer-term and broader-based studies than the abovementioned studies are needed to better evaluate the effect of mobile phones on HRV.

\section{Mood disorders}

Studies conducted in recent years support that the heart rate variability may be a reflection of the pathology of mood, cognition, and behavior [57]. The heart rate variability can be used as a sensitive method in the examination of association between psychopathology and autonomic dysfunction [58]. It was shown in many studies that heart rate variability was decreased in panic disorder patients, in other words, parasympathetic tone was decreased, and relatively sympathetic dominance arose [59,60].

A decreased vagal tone, an increased sympathetic tone in depressed patients may result in cardiac arrhythmias and sudden death, decreasing the ventricular fibrillation threshold. QT variability also leads to an increase in arrhythmias which is related to the increase in sympathetic tone [61]. It has been reported that the heart rate variability was lower in depressed patients when the heart rate variability of depressed and non-depressed post-MI patients were compared [62].

\section{Tricyclic anti-depressants}

They are effective on heart rate, rhythm, electrical conduction, blood pressure and myocardial contractility.

The heart rate is usually increased in the range of 10-20 pulses/ minute with by anticholinergic effect [63]. These drugs prolong the QTc interval and increase the QT variability. The prolongation of the QT interval shows an arrhythmogenic effect. This arrhythmogenic effect is more significant at high doses and in coronary artery disease. They decrease the heart rate variability $[64,65]$.

\section{Selective Serotonin Reuptake Inhibitors (SSRIs)}

Studies conducted with SSRIs until today have showed that these drugs have a safer and more effective cardiovascular profile than the tricyclic anti-depressants in depressive patients with ischemic heart disease. Selective serotonin reuptake inhibitors (paroxetine, fluoxetine, sertraline) do not have a significant effect on HRV and QT. They may cause a decrease in mortality rate due to their antithrombocyte activities. These agents prevent the accumulation of serotonin in thrombocytes. Thus, thrombocyte activation and aggregation are brought to normal levels in depressed individuals with ischemic heart disease [61].

\section{Sleep}

The parasympathetic nervous system begins to show its activity with the onset of sleep and its activity is maintained at high levels throughout the Non-REM sleep. On the other hand, the activity of the parasympathetic nervous system shows a decline towards the level of alertness during REM sleep, however still continues slightly high. The activity of sympathetic nervous system progresses low during Non-REM sleep and high during REM sleep within this balance. HF component shows a rapid increase with the onset of sleep and progresses high throughout all sleep stages (both REM sleep and Non-REM sleep). When Non-REM and REM sleep were compared, the HF was found to be higher in the period of Non-REM sleep compared to REM sleep. LF component decreases similarly to that of sympathetic nervous system activity during the period of Non-REM sleep and reaches the lowest level, in particular during slow-wave sleep. The activity of sympathetic nervous system rises above the alertness level during REM sleep, while the LF increases. LF/HF ratio decreases during Non-REM sleep and increases during REM sleep, and comes to close levels of alertness $[66,67]$. 


\section{Conclusion}

The heart rate variability is a considerably powerful and reliable tool of assessing the fluctuations in the autonomic nervous system that can be observed in healthy individuals or in many diseases, such as those mentioned above. Depending on physical and mental stress, exercise, respiration and metabolic values, alterations (fluctuations) are experienced in the heart rate variability. HRV that provides information about the sympathetic-parasympathetic balance is used as a measure of the cardiac autonomic tone and as an indicator of the cardiorespiratory system $[12,47]$.

HRV may gain a place as a non-invasive method in terms of managing risk and treatment and assessing the efficacy of drugs in cardiovascular diseases. A global decrease in HRV of post-acute myocardial infarction cases is an important indicator of arrhythmiarelated mortality. HRV values, which are measured in primary neurological disorders progressing with alterations in autonomic functions such as Parkinson's disease, multiple sclerosis, GullianBarré syndrome, Shy Drager syndrome, and in secondary autonomic neurological disorders concomitant with conditions such as diabetes mellitus, spinal cord injuries, alcoholism, and in diseases in which sympathovagal factors are considered to play an important role such as long QT syndrome, may provide useful information on early diagnosis and treatment efficacy of the disease [6,47]. Long-term and broadbased studies are needed to reliably reveal the sensitivity, specificity, and predictive value of the heart rate variability in aforementioned diseases.

\section{References}

1. La Rovere MT (2007) Heart rate variability. TAPE 5: 26-29.

2. Freeman JV, Dewey FE, Hadley DM, Myers J, Froelicher VF (2006) Autonomic Nervous System Interaction With The Cardiovascular System During Exercise. Prog Cardiovasc Dis 48: 342-362. [Crossref]

3. Task Force of the European Society of Cardiology and the North American Society of Pacing and Electrophysiology (1996) Heart rate variability. Standards of measurement, physiological interpretation, and clinical use. Eur Heart J 17: 354-381. [Crossref]

4. Guilleminault C, Connolly SJ, Winkle RA (1983) Cardiac arrhythmia and conduction disturbances during sleep in 400 patients with sleep apnea syndrome. Am J Cardiol 52: 490-494. [Crossref]

5. Bixler EO, Vgontzas AN, Ten Have T, Tyson K, Kales A (1998) Effects of age on sleep apnea in men: I. Prevalence and severity. Am J Respir Crit Care Med 157: 144-148. [Crossref]

6. Task Force of the European Society of Cardiology and the North American Society of Pacing and Electrophysiology (1996) Heart rate variability: standards of measurement, physiological interpretation and clinical use. Circulation 93: 1043-1065. [Crossref]

7. Lewis MJ (2005) Heart rate variability analysis: a tool to assess cardiac autonomic function. Comput Inform Nurs 23: 335-341. [Crossref]

8. Shaffer F, Ginsberg JP (2017) An Overview of Heart Rate Variability Metrics and Norms. Front Public Health 5: 258. [Crossref]

9. Tarvainen MP, Lipponen J, Niskanen JP, Ranta-Aho P (2018) Kubios HRV Version 3 - User's Guide.

10. Pagani M, Lombardi F, Guzzetti S, Rimoldi O, Furlan R, et al. (1986) Power spectral analysis of heart rate and arterial pressure variabilities as a marker of sympatho-vagal interaction in man and conscious dog. Circ Res 59: 178-193. [Crossref]

11. Vollmer M (2015) A robust, simple and reliable measure of heart rate variability using relative RR intervals. Computing in Cardiology Conference (CinC), Nice, France.

12. Kayıç̧ığlu M, Payzın S (2001) Heart Rate Variability. Arch Turk Soc Cardiol 29: 238-245.

13. Ahmad S, Ramsay T, Huebsch L, Flanagan S, McDiarmid S, et al. (2009) Continuous multi-parameter heart rate variability analysis heralds onset of sepsis in adults. PLos One 4: e6642. [Crossref]

14. Kleiger RE, Stain PK, Bigger JT Jr (2005) Heart Rate Variability: Measurement an Clinical Utility. Ann Noninvasive Electrocardiol 10: 88-101. [Crossref]
15. Grunstein RR, Wilcox I, Yang TS, Gould Y, Hedner J (1993) Snoring and sleep in men: association with central obesity and hypertension. Int J Obesity 17: 533-540. [Crossref]

16. Tekiner F, Gemici K, Çiçek D, EkicibaşıE, FazlıogluM, et al. (2004) Correlation Between Heart Rate Variability Indices and QT Durations in Heart Failure. Arch Turk Soc Cardiol 32: 232-238.

17. Kurtoğlu E, Aktürk E, Korkmaz H, Ataş H, Cuğlan B, et al. (2013) Impaired heart rate variability in patients with mitral annular calcification: An observational study. Anat Card J 13: 668-674. [Crossref]

18. Liao D, Cai J, Barnes RW, Tyroler HA, Rautaharju P, et al. (1996) Association of cardiac autonomic function and the development of hypertension: The ARIC study. Am J Hypertens 9: 1147-1156. [Crossref]

19. Singh JP, Larson MG, Tsuji H, Evans JC, O’Donnell CJ, et al. (1998) Reduced heart rate variability and new-onset hypertension: insights into pathogenesis of hypertension: The Framingham Heart Study. Hypertension 32: 293-297. [Crossref]

20. Ernst G (2017) Hidden Signals-The History and Methods of Heart Rate Variability Front Public Health 5: 265. [Crossref]

21. Kriete A (2013) Robustness and aging--a systems-level perspective. Biosystems 112: 37-48. [Crossref]

22. Khandoker AH, Palaniswami M, Begg RK (2008) A comparative study on approximate entropy measure and poincaré plot indexes of minimum foot clearance variability in the elderly during walking. J Neuroeng Rehabil 5: 4. [Crossref]

23. Fishman M, Jacono FJ, Park S, Jamasebi R, Thungtong A, et al. (2012) A method for analyzing temporal patterns of variability of a time series from Poincaré plots. $J$ Appl Physiol 113: 297-306. [Crossref]

24. de Abreu LC, Roque AL, de Castro Bianca CR, de Souza ACA, Vanderlei LCM, et al. (2014) Responses of the geometric indices of heart rate variability to the active orthostatic test in women. Medical Express 1: 351-355.

25. Jeppesen J, Beniczky S, Johansen P, Sidenius P, Fuglsang-frederiksen A (2014) Using Lorenz plot and Cardiac Sympathetic Index of heart rate variability for detecting seizures for patients with epilepsy. Conf Proc IEEE Eng Med Biol Soc 2014: 45634566. [Crossref]

26. James DV, Reynolds LJ, Maldonado-Martin S (2010) Influence of the duration of a treadmill walking bout on heart rate variability at rest in physically active women. $J$ Phys Act Health 7: 95-101. [Crossref]

27. Gerritsen J, Dekker JM, TenVoorde BJ, Kostense PJ, Heine RJ, et al. (2001) Impaired autonomic function is associated with increased mortality, especially in subjects with diabetes, hypertension, or a history of cardiovascular disease: The Hoorn Study. Diabetes Care 24: 1793-1798. [Crossref]

28. La Rovere MT, Bigger JT Jr, Marcus FI, Mortara A, Schwartz PJ (1998) Baroreflex sensitivity and heart-rate variability in prediction of total cardiac mortality after myocardial infarction. ATRAMI (Autonomic Tone and Reflexes After Myocardial Infarction) Investigators. Lancet 351: 478-484. [Crossref]

29. Forslund L, Björkander I, Ericson M, Held C, Kahan T, et al. (2002) Prognostic implications of autonomic function assessed by analyses of catecholamines and heart rate variability in stable angina pectoris. Heart 87: 415-422. [Crossref]

30. Casolo G, Balli E, Taddei T, Amuhasi J, Gori C (1989) Decreased spontaneous hear rate variability in congestive heart failure. Am J Cardiol 64: 1162-1167. [Crossref]

31. Deegan PC, McNicholas WT (1996) Predictive value of clinical features for the obstructive sleep apnoea syndrome. Eur Respir J 9: 117-124. [Crossref]

32. Guilleminault C (1994) Clinical features and evaluation of obstructive sleep apnea. In Kryger MH, Roth T, Dement WC, editors. Principles and Practice of Sleep Medícine. Philadelphia. WB Saunders, 667-677.

33. Kleiger RE, Miller JP, Bigger JT Jr, Moss AJ (1987) Decreased Heart Rate Variability and its association with increased mortality after acute myokardial infarktion. Am J Cardiol 59: 256-262. [Crossref]

34. La Rovere MT, Pianna GT, Maestri R, Mortara A, Capomolla S, et al. (2003) Short term heart rate variability strongly predicts sudden cardiac death in chronic heart failure patients. Circulation 107: 565-570. [Crossref]

35. Kuehl M, Stevens MJ (2012) Cardiovascular autonomic neuropathies as complications of diabetes mellitus. Nature Rev Endocrin 8: 405-416. [Crossref]

36. Bixler EO, Vgontzas AN, Ten Have T, Tyson K, Kales A (1998) Effects of age on sleep apnea in men: I. Prevalence and severity. Am J Respir Crit Care Med 157: 144-148. [Crossref] 
37. Karakaya İ, Gürbüz S, Tümer C, Akgül F, Yalçın F (2011) Investigating of the Heart Rate Variability According to Prolapse Degree in Patients Possessing Mitral Valve Prolapse. J Cardiovasc Sci 23: 221-229.

38. Bernardi L, Salvucci F, Suardi R, Soldá PL, Calciati A, et al. (1990) Evidence for an intrinsic mechanism regulating heart rate variability in the transplanted and the intact heart during submaximal dynamic exercise? Cardiovasc Res 24: 969-981. [Crossref]

39. Fallen EL, Kamath MV, Ghista DN, Fitchett D (1988) Spectral analysis of heart rate variability following human heart transplantation: evidence for functional reinnervation. J Auton Nerv Syst 23: 199-206. [Crossref]

40. Halpert I, Goldberg D, Levine AB, Levine TB, Kornberg R, et al. (1996) Reinnervation of the transplanted human heart as evidenced from heart rate variability studies. Am J of Cardiol 77: 180-183. [Crossref]

41. Alyan Ö, Kaçmaz F, Özdemir Ö, Karahan Z, Taşkesen T, et al. (2008) High levels of high-sensitivity C-reactive protein and impaired autonomic activity in smokers. Arch Turk Soc Cardiol 36: 368-375. [Crossref]

42. Thayer JF, Yamamato SS, Brosschot JF (2010) The relationship of autonomic imbalance, heart rate variability and cardiovascular disease risk factors. Int $J$ Cardiol 141: 122-131. [Crossref]

43. Şahiner L, Çiftçi O, Yavuz B (2006) QT Dynamicity and Heart Rate Variability in Patients with Hypertension.

44. Sarıkaya S, ŞahinŞ, Akyol L, Altunkaş F, Aktaş T, et al. (2014) Assessment of Autonomic Functions in Patients with Obstructive Sleep Apnea Syndrome.

45. Devos D, Kroumova M, Bordet R, Vodougnon H, Guieu JD, et al. (2003) Heart rate variability and Parkinson's disease severity. J Neural Transm 110: 997-1011. [Crossref]

46. AlkanA, Eker H, Hallığlu O, Çıtırık D, Parlak E, et al. (2013) Comparison of Obese and Athletic Children Based on Heart Rate Variability.

47. Malik M (1998) Heart Rate Variability. Curr Opin Cardiol 13: 36-44. [Crossref]

48. Zuanetti G, Latini R, Neilson JMM, Schwartz PJ, Ewing DJ (1991) Heart rate variability in patients with ventricular arrhythmias: effect of antiarrhythmic drugs. $J$ Am Coll Cardiol 17: 604-612. [Crossref]

49. Lombardi F, Torzillo D, Sandrone G, Dalla Vecchia L, Finocchiaro ML, et al. (1992) Beta Blocking effect of propafenone based on spectral analyze of heart rate variability. Am J Cardiol 70: 1028-1034. [Crossref]

50. Bigger JT Jr, Rolnitzky LM, Steinman RC, Fleiss JL (1994) Predicting mortality after myocardial infarction from the response of RR variability to antiarrhythmic drug therapy. J Am Coll Cardiol 23: 733-740. [Crossref]

51. Beckheit S, Tangella M, El-Sakr A, Rasheed Q, Craelius W, et al. (1990) Use of heart rate spectral analysis to study the effects calcium channel blockers on sympathetic activity after miyokardial infarction. Am Heart $J$ 119: 79-85. [Crossref]
52. Lipsitz LA, Mietus S, Moody GB, Goldberger AL (1990) Spectral charactheristics of heart rate variability before and during postural tilt: relations to aging and risk of syncope. Circulation 81: 1803-1810. [Crossref]

53. Tamer A, Gündüz H, Özyıldırım S (2009) The cardiac effects of a mobile phone positioned closest to the heart. Anatol J Cardiol 9: 380-384. [Crossref]

54. Yildız M, Derya M. Effects of Cell Phones on Power Spectral Density of Heart Rate Variability, 2007.

55. Wile J, Johansson A, Kalezic N, Lyskov E, Sandstro M (2006) Psychophysiologica Tests and Provocation of Subjects With Mobile Phone Related Symptoms. Bioelectromagnetics 27: 204-214. [Crossref]

56. IEGMP (lndependent Expert Group on Mobile Phones) Report. Mobile Phones and Health, 2001

57. Thayer JF, Lane RD (2000) A model of neurovisceral integration in emotion regulation and dysregulation. J Affect Disord 61: 201-216. [Crossref]

58. Yetkin S, Erdamar A, Yokuşoğlu M, Özgen F, Aydın H (2014) Heart Rate Variabilty During Sleep in Patients with Panic Disorders. J Turk Sleep Med 1: 28-32.

59. Klein E, Cnaani E, Harel T, Braun S, Ben-Haim SA (1995) Altered heart rate variability in panic disorder patients. Biol Psychiatry 37: 18-24. [Crossref]

60. Hamada T, Koshino Y, Misawa T, Isaki K, Gejyo F (1998) Mitral valve prolapse and autonomic function in panic disorder. Acta Psychiatr Scand 97: 139-143. [Crossref]

61. Çay S, Korkmaz Ş (2005) Antidepressant and antipsychotic treatment in patients with cardiac diseases: drug choice and issues to be considered. Arch Turk Soc Cardiol 33 : 233-240.

62. Carney RM, Blumenthal JA, Stein PK, Watkins L, Catellier D, et al. (2001) Depression, heart rate variability, and acute myocardial infarction. Circulation 104: 2024-2028. [Crossref]

63. Roose SP, Glassman AH (1989) Cardiovascular effects of TCAs in depressed patients with and without heart disease. J Clin Psychiatry Monograph 7: 1-19.

64. Yeragani VK (2000) Major depression and long-term heart period variability. Depress Anxiety 12: 51-52. [Crossref]

65. Yeragani VK, Pohl R, Balon R, Ramesh C, Glitz D, et al. (1991) Heart rate variability in patients with major depression. Psychiatry Res 37: 35-46. [Crossref]

66. Versace F, Mozatto M, Tona GM, Cavallero C, Stegagno L (2003) Heart rate variability during sleep as a function of the sleep cycle. Biol Psychol 63:149-162. [Crossref]

67. Yang CC, Lai CW, Lai HY, Kuo TB (2002) Relationship between electroencephalogram slow-wave magnitude and heart rate variability during sleep in humans. Neurosci Lett 329: 213-216. [Crossref]

Copyright: (C2018 Y1lmaz M. This is an open-access article distributed under the terms of the Creative Commons Attribution License, which permits unrestricted use, distribution, and reproduction in any medium, provided the original author and source are credited. 